\title{
Prototipe Green Internet Technology Guna Mendukung Infrastruktur Desa Pintar
}

\author{
Nurchim ${ }^{1^{*}}$, Afu Ichsan Pradana ${ }^{2}$ \\ ${ }^{12}$ Fakultas Ilmu Komputer, Universitas Duta Bangsa Surakarta \\ nurchim@udb.ac.id ${ }^{1 *}$, afu ichsan@udb.ac.id ${ }^{2}$
}

\begin{tabular}{l} 
Article Info \\
\hline Article history: \\
Received 2019-11-14 \\
Revised 2019-11-26 \\
Accepted 2019-11-27 \\
\hline
\end{tabular}

Keyword:

access point, internet,

IoT,

renewable energy, smart village.

\begin{abstract}
The internet has become one of the supporting infrastructures for the successful implementation of the smart village. In Indonesia, many village governments have provided public internet access points in the village area. However, the implementation of this access point has not been able to reach all rural areas due to geographical constraints and the availability of electricity. This study aims to make a prototype of an internet access point with solar power, also known as Green Internet Technology. This prototype is done by using a Design-Based Research (DBR) approach which consists of six steps including (1) focusing, (2) understanding, (3) defining, (4) understanding, (5) building, (5) building and (6) tests. The prototype Green Internet Technology has 3 main parts including (1) solar power systems, (2) internet access point systems and (3) solar monitoring systems. Test results in the real environment that the solar power system and internet access point can work 24 hours a day. But going forward, solar monitoring systems need to be reviewed, especially in the stability of the performance of current and voltage sensor devices.
\end{abstract}

\section{Copyright (C) 2019 Journal of Applied Informatics and Computing.} All rights reserved.

\section{Pendahuluan}

Kunci keberhasilan program desa pintar berawal dari transformasi digital khususnya penyediaan internet yang menjadi infrastruktur utamanya [1]. Melalui internet dapat dijadikan sebagai katalisator perubahan dalam bidang ekonomi, pendidikan, kesehatan dan kinerja pemerintahan desa [2]. Saat ini, pembangunan infrastruktur internet telah banyak dilakukan berupa pendirian tower internet (hotspot) [3] di lingkungan desa seperti yang ditunjukkan pada Gambar 1. Namun, keberagaman letak geografis desa di Indonesia [2] dan ketersediaan listrik [4] menjadikan tidak semua wilayah desa dapat dibangun konektivitas hotspot.

Teknologi jaringan hotspot terbaru, dapat dikembangkan memanfaatkan perangkat access point nirkabel. Penggunaan access point nirkabel ini diharapkan dapat memperluas jangkauan area jaringan hotspot tanpa memerlukan sambungan kabel antar perangkat lainnya [5]. Sedangkan, solusi permasalahan sumber daya listrik dapat menggunakan Pembangkit Listrik Tenaga Surya (PLTS). PLTS berpotensi menjadi sumber listrik alternatif di Indonesia yang dilalui garis khatulistiwa, sehingga memungkinkan memperoleh cahaya matahari dalam jumlah lebih banyak [6][7].

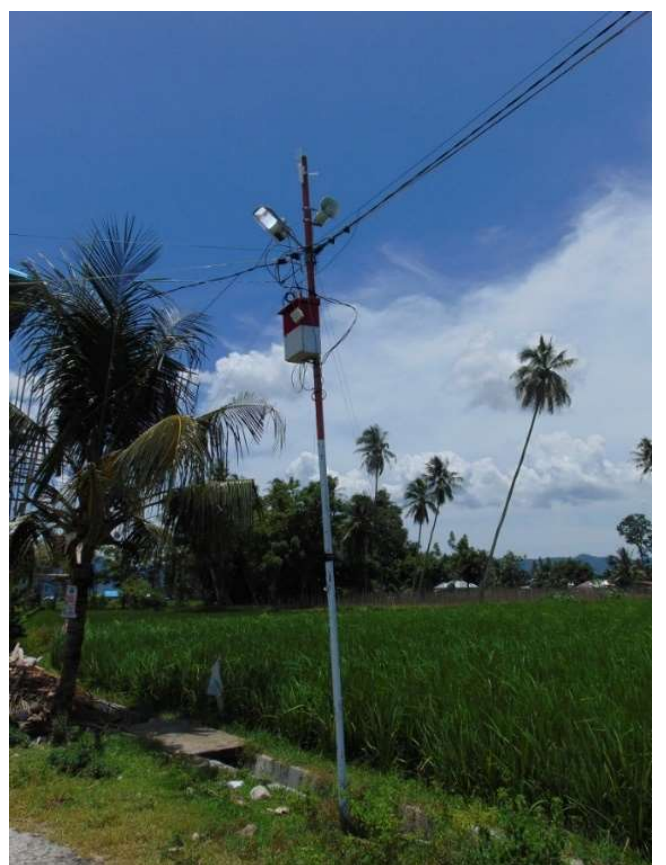

Gambar 1.Contoh penyediaan hotspot di salah satu desa Indonesia yang menggunakan sistem pengkabelan dan membutuhkan sumber daya listrik. Sumber:[1] 
Tujuan penelitian ini adalah menyediakan prototipe access point internet memanfaatkan tenaga surya. Penyediaan access point tenaga surya diharapkan dapat mengurangi ketergantungan pada proses pengkabelan dan ketersediaan listrik sehingga dapat mempercepat pembangunan infrastruktur internet. Selain itu, mendukung untuk pengembangan sistem lainnya seperti IoT, CCTV nirkabel dan lampu penerangan tenaga surya [1]. Oleh karena itu, hasil prototipe ini dapat digunakan untuk mendukung mewujudkan desa pintar di Indonesia.

Adanya access point nirkabel memungkinkan pengguna internet dalam jumlah yang banyak dapat terhubung secara wireless (tanpa kabel) dengan cepat dan mudah [8]. Wireless ini memiliki parameter meliputi frekuensi, bandwidth dan jangkauan transmisi [9]. Pada access point wireless yang dikembangkan, menggunakan model wireless repeater. Melalui model wireless repeater ini dapat ditambahkan extension point hotspot sehingga cakupannya menjadi luas [10]. Dengan demikian, pembangunan infrastruktur internet cukup memasang perangkat ini sesuai dengan titik yang telah ditentukan tanpa harus melakukan instalasi kabel. Selain itu, pelaksanaan instalasi lebih fleksibel dan konfigurasinya tidak begitu sulit sehingga dampaknya masyarakat desa dapat lebih mudah mengakses internet dimanapun berada [11].

Segi sumber daya listrik, PLTS dianggap sebagai alternatif yang menjanjikan dalam penyediaan energi listrik [12]. Di Indonesia, tenaga surya memiliki pontesi paling besar untuk digunakan sebagai sumber energi listrik [13] seperti yang ditunjukkan pada Tabel 1 .

TABEL I

Potensi ENERGI TERBARUKAN DI INDONESIA

\begin{tabular}{|c|l|c|}
\hline No & \multicolumn{1}{|c|}{ Tipe Energi } & Potensi (Mw) \\
\hline 1 & Geothermal & 29,544 \\
\hline 2 & Hydro & 75,091 \\
\hline 3 & Mini dan Microhydro & 19,385 \\
\hline 4 & Bioenergy & 32,654 \\
\hline 5 & Solar Energy & 207,898 \\
\hline 6 & Wind energy & 60,647 \\
\hline 7 & Ocean Energy & 17,989 \\
\hline
\end{tabular}

Cara kerja PLTS ini cukup dengan mengkonversi cahaya menjadi listrik oleh panel surya dan hasilnya dapat dialirkan langsung ke terminal listrik pengguna [14]. Biaya implementasi panel surya ini juga mengalami penurunan sangat banyak, akibat adanya kemajuan teknologi pembuatan panel surya terbaru [15]. Penggunaan tenaga surya ini, dapat dijadikan sumber energi listrik perangkat access point nirkabel sehingga tidak perlu khawatir dengan ketersediaan listrik di lingkungan desa.

\section{METODE PENELITIAN}

Pembuatan prototipe ini dilakukan dengan pendekatan Design Based Research (DBR). Pendekatan DBR didasari dari hubungan antara desain dan metode ilmiah dengan permasalahan yang terjadi di lapangan [16]. Tahapan DBR terdiri enam langkah [17] meliputi (1) focus, (2) understand, (3) define, (4) conceive, (5) build dan (6) test sebagaimana penjelasan setiap tahapan ditunjukkan pada Gambar 2.

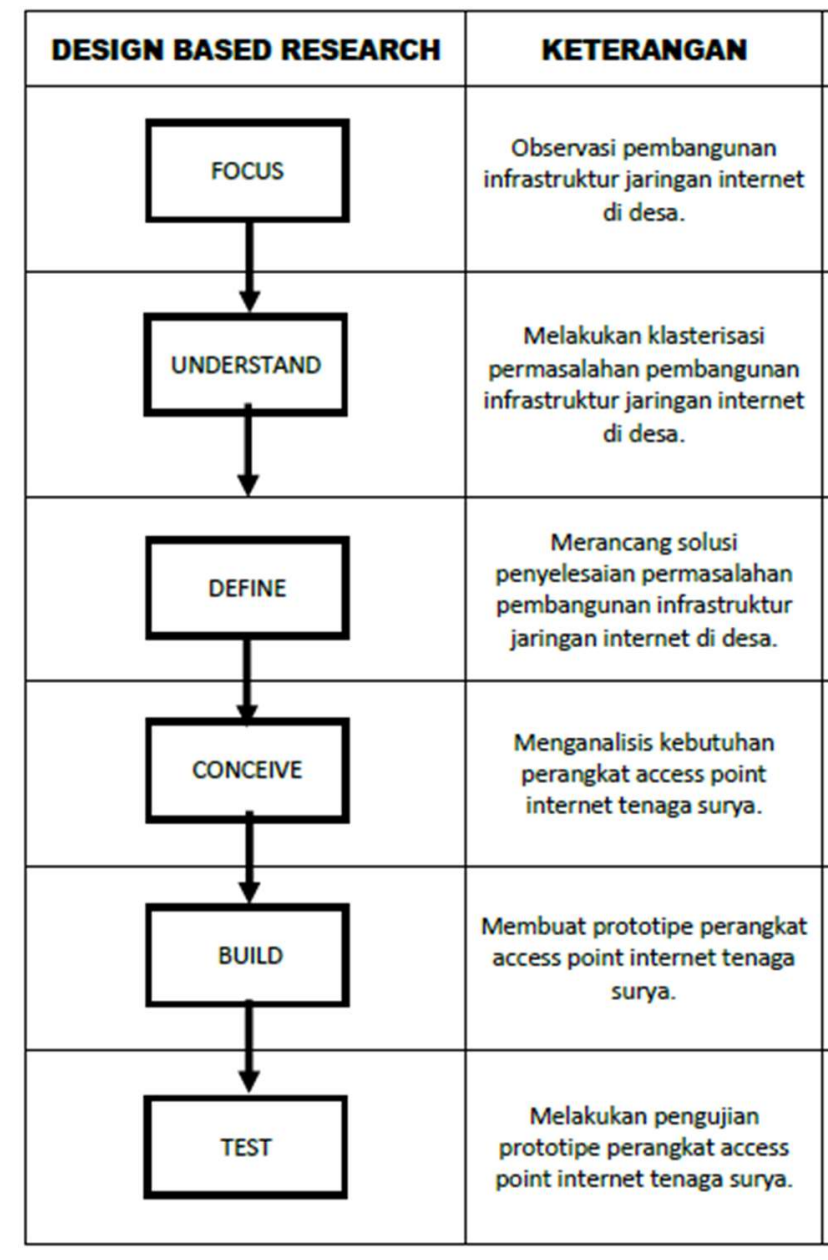

Gambar 2. Tahapan penelitian.

Hasil penelitian ini diharapkan sebagai terobosan dalam pembangunan jaringan internet, sehingga memungkinkan digunakan untuk transformasi kondisi agar menjadi lebih baik [18].

\section{HASIL DAN PEMBAHASAN}

\section{A. Focus dan understand}

Tahapan focus dan understand merupakan tahapan yang digunakan untuk menentukan topik, ruang lingkup dan permasalahan penelitian [17]. Topik yang menjadi pembahasan dalam penelitian ini yakni pembangunan infrastruktur internet di desa wilayah Indonesia. Observasi pembangunan infrastruktur internet dilakukan di Desa Lamahu, Bone Bolango, Gorontalo sejak tahun 2018. Di desa tersebut, pembangunan infrastruktur internet telah dilakukan sebanyak 64 titik yang tersebar di wilayah desa [1]. Implementasi infrastruktur internet tersebut dilakukan dengan menyambungkan kabel jaringan internet dan listrik dari tiang 
satu ke tiang lainnya seperti yang ditunjukkan pada Gambar 3. Dari hasil wawancara dengan Kepala Desa, diperoleh kendala ketidakstabilan koneksi internet karena seringnya kabel yang putus dan daya listrik yang terbatas untuk memasok listrik ke seluruh perangkat jaringan internet. Oleh karena itu, diperlukan pembangunan jaringan internet dengan konsep efisiensi energi [19] yang dikenal dengan istilah Green Internet Technology [20][21].

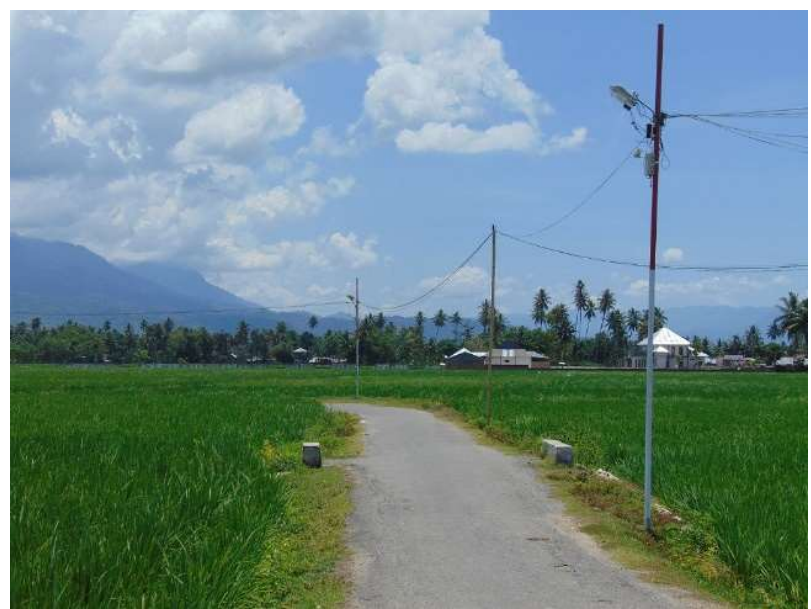

Gambar 3. Implementasi jaringan internet yang menggunakan model penyambungan kabel antar tiang. Sumber: [1]

\section{B. Define}

Selanjutnya fase define digunakan untuk menganalisis permasalahan yang timbul dan mengidentifikasi konsep awal dari solusi yang ditawarkan [17]. Konsep yang ditawrkan bahwa, desain access point internet tenaga surya ini dibagi menjadi tiga bagian yaitu (1) tenaga surya menjadi sumber daya listrik utama yang bersifat renewable energy untuk keseluruhan perangkat, (2) access point internet berfungsi sebagai pemancar internet agar dapat diakses public dan (3) sistem monitoring tenaga surya berbasis cloud storage server memanfaatkan koneksi internet yang dipancarkan oleh access untuk mengirimkan data monitoring konversi energi surya [22]. Cloud storage sebagai artefak teknologi informasi [23] digunakan sebagai media penyimpanan data. Detail ketiga bagian tersebut ditampilkan pada Gambar 4.

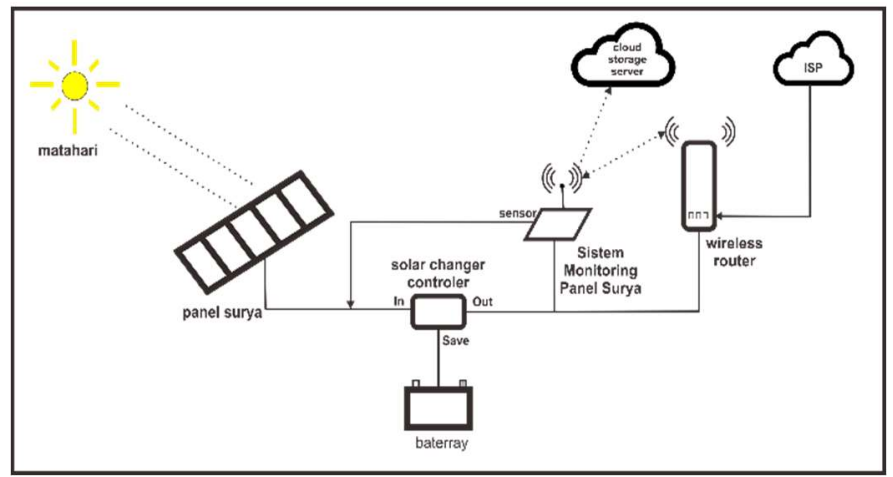

Gambar 4. Desain prototipe access point tenaga surya (Sumber: [22])

\section{Conceive}

Sebagaimana meninjau hasil desain maka pembuatan prototipe access point internet berbasis tenaga surya atau Green Internet Technology ini perlu dilakukan analisis kebutuhan perangkat. Hasil analisis kebutuhan perangkat tersebut ditampilkan pada Tabel 2.

TABEL II

ANALISIS KEBUTUHAN PERANGKAT

\begin{tabular}{|l|l|}
\hline Nama Bagian & Perangkat Utama \\
\hline \multirow{3}{*}{ Sistem Tenaga Surya } & - Panel surya; \\
& - Baterai; \\
& - Solar charge controller. \\
\hline Sistem Access Point Internet & Wireless router \\
\hline \multirow{5}{*}{ Sistem Monitoring Tenaga Surya } & - Sensor arus \\
& - Sensor tegangan \\
& - Mikrokontroler \\
& - Cloud storage server \\
& - Domain \\
\hline
\end{tabular}

\section{Build and test}

Hasil pembuatan prototipe Green Internet Technology ini dilakukan pengujian dengan pendekatan hybrid modelling yakni kombinasi dari pengujian fisik dan pengujian secara langsung di lingkungan nyata [24].

\section{Pengujian Fisik}

Tahapan ini digunakan untuk menguji bahwa semua perangkat dapat berfungsi dengan benar. Langkah yang dilakukan dengan melakukan instalasi sederhana semua perangkat sesuai dengan hasil desain dalam waktu 1 hari seperti yang ditunjukkan pada Gambar 5.

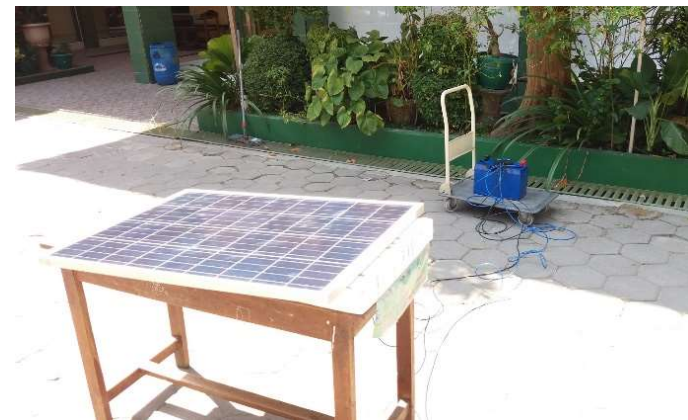

(a) Pengujian fungsi perangkat panel surya

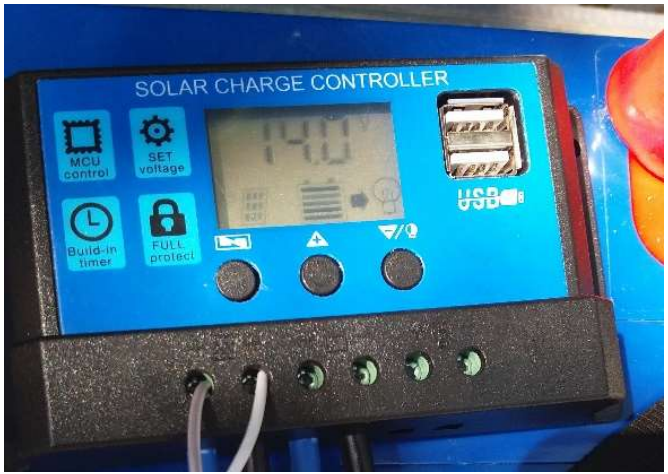

(b) Hasil konversi listrik dapat disimpan ke baterai Gambar 5. Pengujian fungsi perangkat prototipe green internet technology 
Dari hasil uji perangkat ini bahwa perangkat access point dapat berfungsi dengan sumber listrik yang dihasilkan dari panel surya.

\section{Pengujian di lingkungan nyata}

Pengujian di lingkungan nyata dilakukan dengan memasang prototipe Green Internet ini langsung berinteraksi dengan lingkungan yakni di atap gedung Fakultas Ilmu Komputer Universitas Duta Bangsa Surakarta ditunjukkan pada gambar 6.

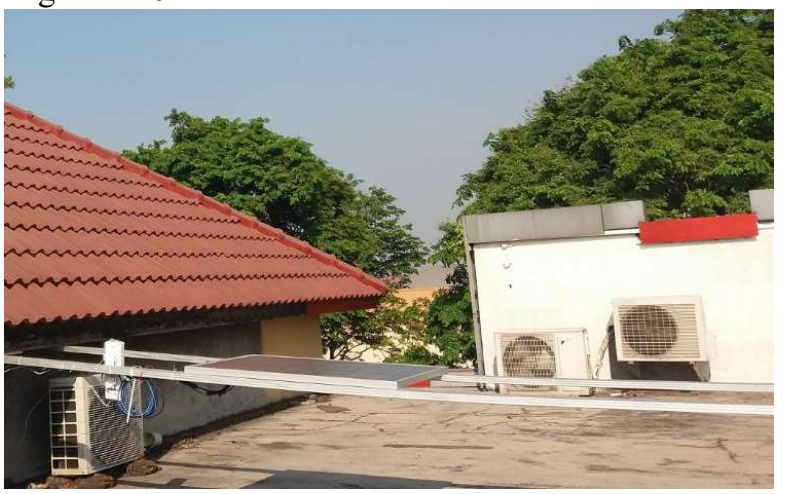

(a) Simulasi panel surya dan access point di lingkungan nyata

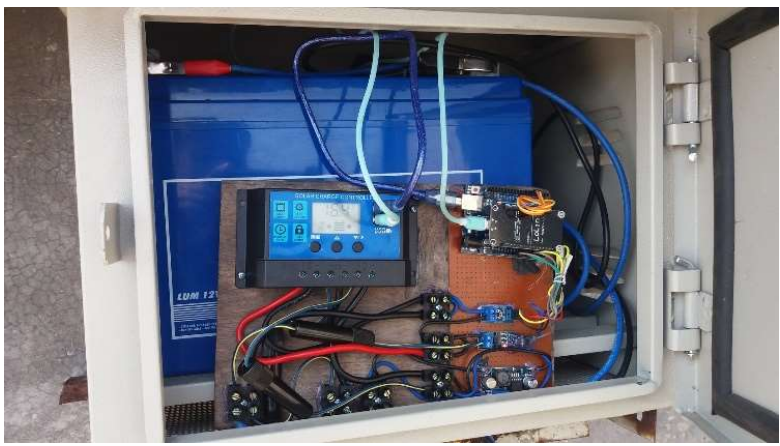

(b) Baterai dan sistem monitoring tenaga surya

Gambar 6. Pengujian prototipe green internet technology di lingkungan nyata

Pemantauan kinerja Green Internet Technology ini dilakukan dengan mengakses online data konversi energi listrik yang dihasilkan panel surya. Data konversi tersebut dikirim ke cloud storage setiap 1 menit, memanfaatkan koneksi internet yang dipancarkan oleh access point yang sumber listriknya berasal dari tenaga surya. Analisis kinerja sistem dapat dilakukan dengan mengecek keberhasilan pengiriman data konversi setiap 1 menit maka dapat disimpulkan bahwa sistem access point internet tenaga surya ini dapat bekerja sesuai dengan fungsinya seperti yang ditampilkan pada Gambar 7. Hasil evaluasi data konversi listrik yang dihasilkan tenaga surya didapatkan bahwa ketika memperoleh arus (I) tinggi maka nilai tegangan (V) rendah. Dan sebaliknya apabila memperoleh arus (I) rendah maka nilai tegangan (V) tinggi. Kondisi ini sesuai dengan hubungan grafik hubungan IV panel surya [25][26]. Arus tinggi ini diperoleh ketika panel surya memperoleh cahaya matahari maksimal. Kendala yang muncul selama proses pengujian prototipe Green Internet Technology ini yaitu ketidakstabilan pembacaan perangkat sensor arus dan tegangan pada sistem monitoring tenaga surya. Mengenai sistem tenaga surya dan access point dapat bekerja stabil 24 jam seperti yang ditampilkan pada gambar 8 .

\section{KESIMPULAN}

Protipe access point internet tenaga surya ini telah menerapkan konsep efisiensi energi atau Green Internet Technology khususnya pada pemanfaatan tenaga surya sebagai sumber listrik yang bersifat renewable energy. Pembuatan prototipe green internet terdiri dari tiga bagian yakni (1) sistem tenaga surya, (2) sistem access point internet dan (3) sistem monitoring tenaga surya. Analisis kinerja prototipe Green Internet Technology dilakukan dengan cara mengakses sistem monitoring tenaga surya secara online yakni apabila data pembacaan perangkat sensor arus dan tegangan listrik hasil konversi panel surya berhasil dikirimkan ke cloud storage server setiap 1 menit maka sistem disimpulkan bekerja. Berdasarkan hasil uji lapangan, prototipe Green Internet Technology bahwa sistem tenaga surya dan access point dapat bekerja selama 24 jam setiap hari. Namun, pada sistem monitoring tenaga surya sering terjadi ketidakstabilan perangkat sensor. Oleh karena itu, untuk penelitian selanjutnya dapat dilakukan analisis kelayakan kinerja sensor arus dan tegangan untuk sistem tenaga surya.

\section{UCAPAN TERIMA KASIH}

Terimakasih Direktorat Riset Pengabdian Masyarakat Kementerian Riset, Teknologi dan Pendidikan Tinggi Republik Indonesia yang telah mendanai penelitian ini pada Tahun 2019. Dan tidak lupa terimakasih disampaikan kepada seluruh civitas Universitas Duta Bangsa.

\section{DAFTAR PUSTAKA}

[1] N. Nurchim and I. Nofikasari, "Pemodelan Adopsi Teknologi Digital Guna Mewujudkan Desa Pintar," in Prosiding Seminar Nasional GEOTIK, 2018, pp. 248-254.

[2] A. Sofiyudin and R. A. Nugroho, "Implementasi Cyber Village dalam Mewujudkan Masyarakat Melek Teknologi Informasi dan Komunikasi Berbasis Internet di Daerah Pegunungan (Studi Kasus di Desa Campurejo, Kecamatan Tretep, Kabupaten Temanggung, Jawa Tengah)," J. Wacana Publik, vol. 1, no. 3, pp. 1-15, 2017

[3] R. Yuliawan, Peran Perangkat Desa untuk Mengembangkan Prinsip Transparansi dalam Good Governance pada Pemerintahan Desa (Studi Kasus di Desa Pabelan Kecamatan Kartasura Kabupaten Sukoharjo). Skripsi Fakultas Keguruan dan Ilmu Pendidikan UMS, 2016.

[4] A. Susanto, "Faktor-faktor yang Memengaruhi Perilaku Penggunaan Internet Masyarakat Desa Pasar VI Kualanamu, Deli Serdang Sumatera utara," J. Penelit. POS dan Inform., vol. 5, no. 1, pp. 65-86, 2015.

[5] D. I. Haerudin, L. M. B. Aksara, and M. Yamin, "Implementasi Wireless Distribution System (WDS) pada Hotspot (Studi Kasus: SMK Negeri 1 Kendari)," semanTIK, vol. 3, no. 2, pp. 105-112, 2017.

[6] R. C. Pambudi, R. Hantoro, and H. Cordova, "Analisa Performansi dan Monitoring Berbasis Web Pada Pembangkit Listrik Tenaga Surya di Fakultas Teknologi Industri ITS," J. Tek. ITS, vol. 7, no. 1, 2018.

[7] H. Soonmin, A. Lomi, E. C. Okoroigwe, and L. R. Urrego, "Investigation of solar energy: The case study in Malaysia, Indonesia, Colombia and Nigeria," Int. J. Renew. Energy Res., vol. 9, no. 1, pp. 86-95, 2019. 
[8] A. D. Limantara, A. I. Candra, and S. W. Mudjanarko, "Manajemen Data Lalu Lintas Kendaraan Berbasis Sistem Internet Cerdas Ujicoba Implementasi di Laboratorium Universitas Kadiri," in Seminar Nasional Sains dan Teknologi, 2017, no. November, pp. 1-2.

[9] H. Nugroho and S. A. Siagian, "Analisis Bandwidth Jaringan Wifi Studi Kasus di Telkom Jakarta Pusat," J. ICT Penelit. dan Penerapan Teknol., vol. 4, no. 7, pp. 35-43, 2013.

[10] R. Riska, P. W. Ginta, and P. Patrick, "Analisa dan Implementasi Wireless Extension Point dengan SSID ( Service Set Identifier )," J. Media Infotama, vol. 13, no. 1, pp. 44-54, 2017.

[11] R. D. Harmono, Perancangan Jaringan Hotspot Server Berbasis Mikrotik Menggunakan Metode WDS (Wireless Distribution System). Skripsi Universitas Muria Kudus, 2017.

[12] M. Anwar and Z. Zulwisli, "Pengujian Kinerja Pembangkit Listrik Tenaga Surya untuk Menggerakkan Pompa air," J. Teknol. Inf. Pendidik., vol. 10, no. 3, pp. 44-47, 2017.

[13] J. Jufrizel and M. Irfan, "Perencanaan Teknis dan Ekonomis Pembangkit Listrik Tenaga Surya Sistem On-Grid," in Seminar Nasional Teknologi Informasi, Komunikasi dan Industri (SNTIKI) 9, 2017, pp. 18-19.

[14] Z. Wang, D. Tsonev, S. Videv, and H. Haas, "On the Design of a Solarpanel Receiver for Optical Wireless Communications with Simultaneous Energy Harvesting," IEEE J. Sel. Areas Commun., vol. 33, no. 8, pp. 1612-1623, 2015.

[15] N. S. Lewis, "Research opportunities to advance solar energy utilization," Science (80-. )., vol. 351, no. 6271, 2016.

[16] T. Amiel and T. C. Reeves, "Design-Based Research and Educational Technology: Rethinking Technology and the Research Agenda,"
Educ. Technol. Soc., vol. 11, no. 4, pp. 29-40, 2008.

[17] M. W. Easterday, D. R. Lewis, and E. M. Gerber, "Design-Based Research Process: Problems , Phases , and Applications," in International Conference of Learning Sciences, 2014

[18] A. Dresch, D. P. Lacerda, and J. A. V. Antunes, Design science research: A method for science and technology advancement. 2015.

[19] W. Zhong, R. Yu, S. Xie, Y. Zhang, and D. H. K. Tsang, "Software Defined Networking for Flexible and Green Energy Internet," IEEE Commun. Mag., vol. 54, no. 12, pp. 68-75, 2016.

[20] Y. Suh, K. Kim, A. Kim, and Y. Shin, "A study on impact of wired access networks for green Internet," J. Netw. Comput. Appl., vol. 57 , pp. 156-168, 2015 .

[21] M. Chen, Y. Miao, and I. Humar, OPNET IoT Simulation. 2019.

22] N. Nurchim and A. I. Pradana, "Perancangan Access Point Internet Tenaga Surya Guna Mewujudkan Desa Pintar," in Seminar Nasional Hasil Penelitian dan Pengabdian pada Masyarakat IV, 2019.

[23] R. F. El-Gazzar, F. Wahid, and K. Stendal, "Unpacking knowledge on cloud computing: An umbrella review," Am. Conf. Inf. Syst. 2018 Digit. Disruption, AMCIS 2018, no. 2015, pp. 1-10, 2018.

[24] M. Hall and A. J. Goupee, "Validation of a hybrid modeling approach to floating wind turbine basin testing," Wind Energy, vol. 21, no. 6, pp. 391-408, 2018.

[25] M. Hadjab, S. Berrah, and H. Abid, "Neural network for modeling solar panel," Int. J. Energy, vol. 6, no. 1, pp. 9-16, 2012.

[26] J. Cubas, S. Pindado, and C. De Manuel, "Explicit expressions for solar panel equivalent circuit parameters based on analytical formulation and the lambert W-function," Energies, vol. 7, no. 7, pp. 4098-4115, 2014.

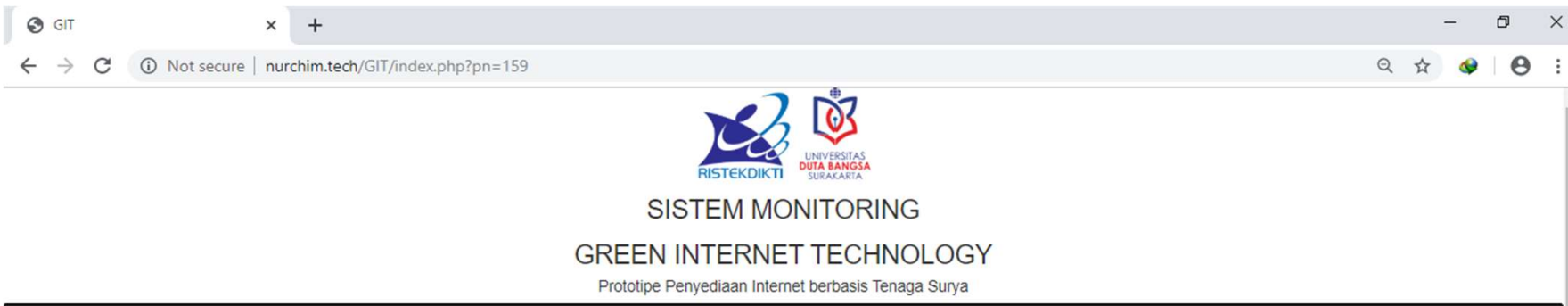

Home Export Excel

\begin{tabular}{|c|c|c|c|c|c|}
\hline NO & JAM & TANGGAL & ARUS (Ampere) & TEGANGAN (Volt) & DAYA (Watt) \\
\hline 4741 & 10:31:09 & 30 October 2019 & 3.01 & 6.24 & 18.78 \\
\hline 4742 & 10:30:19 & 30 October 2019 & 3.01 & 6.15 & 18.51 \\
\hline 4743 & 10:29:28 & 30 October 2019 & 3.01 & 6.24 & 18.78 \\
\hline 4744 & 10:28:38 & 30 October 2019 & 3.03 & 6.17 & 18.70 \\
\hline 4745 & $10: 27: 48$ & 30 October 2019 & 3.03 & 6.2 & 18.79 \\
\hline 4746 & $10: 26: 58$ & 30 October 2019 & 3.08 & 6.08 & 18.73 \\
\hline
\end{tabular}

Gambar 7. Pengiriman data sistem monitoring tenaga surya setiap menit

Data Monitoring Daya Hasil Konversi Tenaga Surya Selama 24 Jam 27 Oktober 2019

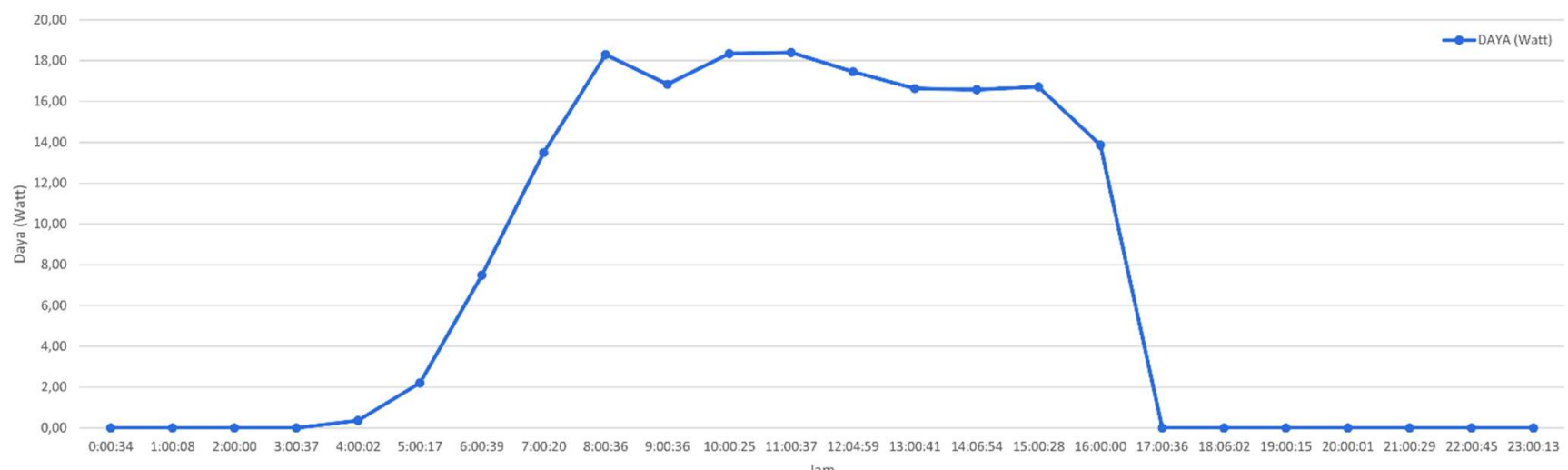

Gambar 8. Grafik monitoring daya tenaga surya selama 24 jam

JAIC Vol. 3, No. 2, Desember 2019: $102-106$ 